Check for updates

The BMJ

Cite this as: BMJ2020;370:m3676 http://dx.doi.org/10.1136/bmj.m3676 Published: 18 September 2020

\section{Covid-19: Testing service wasn't prepared for increased demand, chief admits}

\section{Gareth lacobucci}

England's NHS Test and Trace service wasn't prepared for the increased demand that has seen thousands of people unable to access tests, the head of the service has admitted.

But Dido Harding insisted that the service had followed modelling from the government's Scientific Advisory Group for Emergencies (SAGE) when planning for surges in demand as schools reopened this month.

The past week has seen a growing number of reports of people across England being unable to access covid-19 tests at local sites. ${ }^{1}$ Harding told MPs that current estimates showed that demand was up to four times higher than capacity.

"We built5 our testing capacity plans [for the autumn] based on SAGE modelling. We published our business plan at the end of July, and we are absolutely on track to deliver that," she told MPs on the House of Commons Science and Technology Committee on 17 September.

"I don't think anybody was expecting the really sizeable increase in demand that we've seen over the last few weeks. In none of the modelling was that expected."

But Harding said, "I strongly refute that the system is failing."

She added, "We planned for a sizeable increase in testing capacity in anticipation. As the prime minister said yesterday, plainly we don't have enough today, and we are doing everything in our power to increase the testing capacity."

Her comments came as the latest figures showed that only $14 \%$ of people were receiving their test results within 24 hours of the test being taken, down from $32 \%$ in the previous week. ${ }^{2}$

Harding said that surveys carried out at local testing sites had found that up to a quarter of people coming forward for a test didn't have symptoms, and she emphasised the importance of seeking a test only if you had symptoms.

"Up to $20 \%$ or $25 \%$ of people coming forward for a test do not have symptoms," she said. "It is clear that demand is significantly outstripping the capacity that we have. We need to make sure that we protect the capacity we have for the people that most need it."

Harding confirmed that capacity problems in laboratories were causing delays and that the government had capped the number of tests that local testing sites were allowed to carry out.

"The constraint in the testing system is in the processing and the laboratories. We have to restrict the number of people who are taking tests in the testing sites so that there is no risk of those tests going out of date when they are processed in the labs," she said.

She said that around half of the current testing capacity was being reserved for NHS patients, NHS staff, and care homes. The next priorities were people in hotspot areas, then key workers, most likely teachers, she added.

Harding also confirmed that to boost capacity the UK was using overseas laboratories to process some tens of thousands of test samples.

1 Rimmer A. Covid-19: Doctors call for action after patients are left unable to get tests. BM/2020;370:m3508doi: 10.1136/bmj.m3508.

2 Department for Health and Social Care. Weekly statistics for NHS Test and Trace (England) and coronavirus testing (UK): 3 September-9 September https://assets.publishing.service.gov.uk/government/uploads/system/uploads/attachment_data/file/918615/test-and-trace-week-15.pdf.

This article is made freely available for use in accordance with BMJ's website determined by BMJ. You may use, download and print the article for any lawful, non-commercial purpose (including text and data mining) provided that all copyright notices and trade marks are retained. terms and conditions for the duration of the covid-19 pandemic or until otherwise 